\title{
Evaluation of the Passage Rate Equations in the 2001 Dairy NRC Model
}

\author{
S. Seo, ${ }^{*}$ L. O. Tedeschi, ${ }^{\star}$ C. G. Schwab,† B. D. Garthwaite, $†$ and D. G. Fox ${ }^{\star 1}$ \\ *Department of Animal Science, Cornell University, Ithaca, NY 14853 \\ †Department of Animal and Nutritional Sciences, University of New Hampshire, Durham 03824
}

\begin{abstract}
Dairy ration formulation to meet protein and amino acid requirements with the National Research Council Nutrient Requirements of Dairy Cattle (NRC, 2001) model depends on accuracy of predicting feed passage rates out of the rumen. The NRC (2001) passage rate (Kp) equations were evaluated for validity and sensitivity to input variables in predicting supplies of rumen degraded protein, rumen undegraded protein, and metabolizable protein. The database used in the development of the $3 \mathrm{Kp}$ equations (for dry forage, wet forage, and concentrate) was used to independently derive the 3 equations using a meta-analysis technique. To extract quantitative relationships between statistically significant input variables and rate of passage, a random coefficients model that used each study effect as a random variable was used. The database was comprised of studies that only used rare earth markers. Outliers were identified by acceptance criteria defined a priori or the difference in fit statistic (DFFITS) value; 319, 63, and 139 treatment means were used to develop the Kp equations for dry forage, wet forage, and concentrate, respectively. We found that the sign of the regression coefficient for concentrate content in diet dry matter in the equation for $\mathrm{Kp}$ dry forage was inverted; it should be positive. A sensitivity analysis was conducted with a spreadsheet version of the NRC (2001) model developed for this study, using the Monte Carlo technique. The sensitivity analysis indicated that all Kp predictions were the most sensitive to variation in DM intake, and thus accurate measurement of DM intake is the most important factor in predicting Kp. Predictions for protein supply (rumen degraded protein, rumen undegraded protein, and metabolizable protein) were sensitive to variability in amount of feed crude protein $(\mathrm{CP}, \% \mathrm{DM})$, digestion rate $(\mathrm{Kd})$ of the $\mathrm{B}$ fraction of feed $\mathrm{CP}(\% / \mathrm{h})$, and the $\mathrm{Kp}$ for concentrate $(\% / \mathrm{h})$, due to the high proportion of dietary $\mathrm{CP}$ in lactating dairy rations coming from concentrates. The sensitivity analysis indicated that accurate determinations of DMI, the
\end{abstract}

Received June 21, 2005.

Accepted January 4, 2006.

${ }^{1}$ Corresponding author: dgf4@cornell.edu
$\mathrm{Kd}$ of the $\mathrm{B}$ fraction of feed $\mathrm{CP}$, and feed $\mathrm{CP}$ are the most important variables needed to predict MP supply in lactating dairy cows with the NRC (2001) model. We conclude that the empirical Kp equations in the model are suitable for predicting passage rate in lactating dairy cows. More accurate predictions of Kp will require the development of a more mechanistic model that accounts for more of the biologically important variables (e.g., physical property of particles, liquid flow, and timely variation of intake) affecting passage rate.

Key words: passage rate, nutrient requirement, diet formulation, 2001 NRC model

\section{INTRODUCTION}

The protein model published by the NRC (2001) is being used to update dairy ration formulation programs to improve their accuracy in predicting dietary protein and amino acid requirements to reduce nitrogen excretion and feed cost per kilogram of milk. In this model, the prediction of MP supplied by feeds in the diet depends on the prediction of feed passage rate from the rumen. The NRC (2001) published 3 new equations to predict rate of passage for dry forage, wet forage, and concentrate in dairy cattle. However, it is not possible to evaluate the adequacy of these equations in representing the published data because little documentation on their development was provided, and the equations were not evaluated.

The objectives of this study were 1) to determine the adequacy of the passage rate equations developed by the 2001 Dairy NRC, 2) to conduct sensitivity analyses to identify the most important inputs that need to be measured in applying these equations in ration formulation programs, and 3) to demonstrate the impact that the passage rate equations in the NRC (2001) model have on model predictions of RDP and RUP supplied by the diet.

\section{MATERIALS AND METHODS}

\section{Development of the NRC (2001) Passage Rate Equations}

Database Construction. The database used to develop the passage rate equations for NRC (2001) con- 
tained 1,271 treatment means (observations) from 275 published experiments conducted with dairy and beef cattle. The experiments were published between January 1980 and February 1999 in the following journals: Animal Feed Science and Technology, Animal Production (continued in 1995 as Animal Science), British Journal of Nutrition, Canadian Journal of Animal Science, Grass and Forage Science, Journal of Animal Science, and Journal of Dairy Science. A total of 810 observations in the database measured either forage or concentrate Kp; DMI or DMI as a percentage of BW and BW were reported or could be calculated from information given. Data were excluded for use in equation development for this study using the same criteria as was used by the NRC (2001) committee: 1) if BW was less than $100 \mathrm{~kg}$ (16 observations were excluded), 2) if concentrate was more than $90 \%$ of dietary $\mathrm{DM}$ ( 61 observations were excluded), and 3) if internal markers (e.g., acidinsoluble ash, NDF, or lignin) or external markers other than rare earths were used or if the marker were applied to TMR and not to at least one individual component of the diet (224 out of 673,41 out of 170 , and 27 out of 38 observations in forages, concentrates, and fibrous byproducts, respectively).

Statistical Models and Algorithms Used to Develop the Passage Equations. The same procedures used for developing the equations published by the Dairy NRC Committee (NRC, 2001) were used in this study. The variables used in equation development were chosen based on 3 criteria: 1) could be measured or calculated routinely in the field, 2) had a variance inflation factor less than 10 (Neter et al., 1996), and 3) were statistically favored over other possible candidates. Dry matter intake as percentage of BW was more significant than actual DMI and BW when trial variation was added as a random variable. The selected variables were DMI as percentage of BW (DMIpBW), concentrate as percentage of diet DM (ConcpDM), and NDF content as percentage of forage DM (NDFF; forage Kp prediction equation only). These variables were linearly related with the response variable (i.e., $\mathrm{Kp}$ ) based on preliminary analysis using partial regression.

Significant independent variables for each equation to predict Kp of dry forage (hay and pasture), wet forage (silage) and concentrate were identified by using the backward elimination procedure of multiple regression, which was done using PROC GLM of SAS (SAS Institute Inc., Cary, NC) with trial effect as a random variable. In this step, trial was assumed an additive effect. Nonsignificant $(P>0.05)$ main effects and interactions were removed sequentially from the model. When an acceptable model was generated, 37 observations in dry forages were eliminated due to lack of information of NDFF. With 344, 68, 129, and 11 observations for dry forages, wet forages, concentrates, and fibrous byproducts, respectively, the difference in fits statistic (DFFITS) was estimated and used as the basis for omitting outliers. Data points with absolute values of DFFITS $\geq 0.4$ (a conservative value based on Neter et al., 1996) were omitted. When more than one absolute value of DFFITS was greater than 0.4, data corresponding to the largest value was omitted first, and the model was refitted to examine whether any other absolute value of DFFITS remained $\geq 0.4$. The above procedure continued until no apparent outlier was observed. To prevent the erroneous removal of acceptable observations, data that previously were omitted were added back sequentially to the model and reevaluated. Without outliers, the variables eliminated previously were added and reassessed for statistical significance. After acceptable equations for predicting $\mathrm{Kp}$ for concentrate and dry and wet forages were obtained, they were applied to data for fibrous byproducts. Paired $t$-test analyses showed that the predicted mean of Kp of fibrous byproducts was significantly lower than the observed mean when the equation for predicting $\mathrm{Kp}$ for dry forage was used. In contrast, the predicted mean $\mathrm{Kp}$ of fibrous byproducts was not significantly different from the observed mean when the equation for predicting $\mathrm{Kp}$ of concentrates was used. Thus, data for fibrous byproducts were pooled with concentrate data and the model was refitted according to the same criteria discussed previously. The final database used to develop the passage equations for dry forage, wet forage, and concentrate feeds included 319, 63, and 139 treatment means, respectively. Descriptive statistics for the data used for predicting the passage rate for dry forage, wet forage, and concentrates are shown in Table 1.

A random coefficient model (Littell et al., 1999) was fitted for the prediction equations generated by the procedure described above again using the MIXED procedure of SAS (SAS Institute Inc, Cary, NC) with an unstructured variance-covariance matrix. Individual study, which is fundamentally random (St-Pierre, 2001), was treated as a random class variable. The model, thus, had a variance component of random study effect for the intercept and slope of each predictor variable. The parameter estimates show the relationship between each predictor variable and response variable (i.e., Kp independent of covariance within a study and among studies). Because no interactions between intercept and coefficients were significant, a variance structure that models a different variance component for each random effect without interactions was used to estimate the parameters. The final prediction equations were composed of solutions for the fixed effects of the predictor variables. The linear model for the random coefficient model used in this study is shown below: 
Table 1. Descriptive statistics of the data used to develop the passage rate equations in NRC (2001)

\begin{tabular}{|c|c|c|c|c|c|}
\hline & $\begin{array}{c}\text { No. of } \\
\text { observations }\end{array}$ & Mean & SD & Maximum & Minimum \\
\hline Dry forage & & & & & \\
\hline $\mathrm{BW}, \mathrm{kg}$ & 319 & 380.2 & 164.8 & 745.5 & 117.0 \\
\hline DMI, kg/d & 319 & 9.3 & 5.4 & 26.8 & 2.7 \\
\hline DMI, $\%$ of BW & 319 & 2.5 & 0.7 & 4.1 & 1.0 \\
\hline Concentrate, \% of diet DM & 319 & 19.3 & 19.8 & 85.0 & 0.0 \\
\hline NDF of forage, \% of DM & 319 & 66.5 & 10.8 & 82.7 & 36.1 \\
\hline $\mathrm{Kp}$ for concentrate, $\% / \mathrm{h}$ & 319 & 3.6 & 0.8 & 5.8 & 2.0 \\
\hline Wet forage & & & & & \\
\hline $\mathrm{BW}, \mathrm{kg}$ & 60 & 572.3 & 107.5 & 721.0 & 277.0 \\
\hline DMI, $\mathrm{kg} / \mathrm{d}$ & 60 & 17.2 & 6.5 & 25.3 & 4.6 \\
\hline DMI, $\%$ of BW & 63 & 2.9 & 0.9 & 4.3 & 1.2 \\
\hline Concentrate, \% of diet DM & 63 & 39.3 & 24.3 & 85.0 & 0.0 \\
\hline NDF of forage, \% of DM & 51 & 49.2 & 7.9 & 67.3 & 35.2 \\
\hline $\mathrm{Kp}$ for wet forage, $\% / \mathrm{h}$ & 63 & 4.8 & 0.9 & 6.2 & 2.6 \\
\hline Concentrate & & & & & \\
\hline $\mathrm{BW}, \mathrm{kg}$ & 139 & 541.6 & 139.0 & 745.5 & 173.0 \\
\hline DMI, kg/d & 139 & 16.4 & 6.9 & 26.8 & 5.0 \\
\hline DMI, $\%$ of $\mathrm{BW}$ & 139 & 3.0 & 0.9 & 4.4 & 1.3 \\
\hline Concentrate, $\%$ of diet DM & 139 & 52.2 & 19.9 & 87.3 & 0.0 \\
\hline NDF of forage, \% of DM & 89 & 53.5 & 13.0 & 77.0 & 31.8 \\
\hline $\mathrm{Kp}$ for concentrate, $\% / \mathrm{h}$ & 139 & 6.0 & 1.9 & 11.2 & 2.4 \\
\hline Class of cattle & & rage & $\mathrm{We}$ & age & Concentrate \\
\hline Lactating dairy or beef cow & & & 39 & & 85 \\
\hline Nonlactating or undefined- & & & & & \\
\hline dairy or beef cow & & & 4 & & 9 \\
\hline Growing cattle & & & 20 & & 45 \\
\hline Total number & & & 63 & & 139 \\
\hline
\end{tabular}

$$
\begin{gathered}
y_{i j}=\beta_{0}+b_{0 i}^{*}+\left(\beta_{1}+b_{1 i}^{*}\right) x_{1 i j}+\left(\beta_{2}+b_{2 i}^{*}\right) x_{2 i j} \\
+\left(\beta_{3}+b_{3 i}^{*}\right) x_{3 i j}+e_{i j}
\end{gathered}
$$

where $y_{i j}$ is $\mathrm{Kp}$ of $\mathrm{jth}$ observation in ith study, $\beta_{0}$ is the fixed effect of intercept, $b_{0 i}^{*}$ is the random effect of intercept in ith study, $\beta_{1}$ is the fixed effect of $x_{1}, b_{1 i}^{*}$ is the random effect of $x_{1}$ in ith study, $x_{1 i j}$ is the level of $x_{1}$ (DMIpBW) on jth observation in ith study, $\beta_{2}$ is the fixed effect of $x_{2}, b_{2 i}^{*}$ is the random effect of $x_{2}$ in ith study, $x_{2 i j}$ is the level of $x_{2}(\mathrm{NDFF}$ if applicable) on jth observation in ith study, $\beta_{3}$ is the fixed effect of $x_{3}, b_{3 i}^{*}$ is the random effect of $x_{3}$ in ith study, $x_{3 i j}$ is the level of $x_{3}$ (ConcpDM if applicable), and $e_{i j}$ is the unexplained random effect on jth observation in ith study. The distribution of random effect components is shown below.

$$
\begin{gathered}
\left(\begin{array}{l}
b_{0 i}^{*} \\
b_{1 i}^{*} \\
b_{2 i}^{*} \\
b_{3 i}^{*}
\end{array}\right) \sim i i d N\left(\left[\begin{array}{l}
0 \\
0 \\
0 \\
0
\end{array}\right), \Psi\right] \Psi=\left(\begin{array}{llll}
\sigma_{b_{0}}^{2} & 0 & 0 & 0 \\
0 & \sigma_{b_{1}}^{2} & 0 & 0 \\
0 & 0 & \sigma_{b_{2}}^{2} & 0 \\
0 & 0 & 0 & \sigma_{b_{3}}^{2}
\end{array}\right) \\
e_{i j} \sim \operatorname{iidN}\left(0, \sigma^{2}\right) .
\end{gathered}
$$

The above model can be expressed in terms of a mixed model as

$$
\begin{gathered}
y_{i j}=\beta_{0}+\beta_{1} x_{1 i j}+\beta_{2} x_{2 i j}+\beta_{3} x_{3 i j}+b_{0 i}^{*}+b_{1 i}^{*} x_{1 i j} \\
+b_{2 i}^{*} x_{2 i j}+b_{3 i}^{*} x_{3 i j}+e_{i j}
\end{gathered}
$$

where $\beta_{0}+\beta_{1} x_{1 i j}+\beta_{2} x_{2 i j}+\beta_{3} x_{3 i j}$ is the fixed effect part of the model and $b_{0 i}^{*}+b_{1 i}^{*} x_{1 i j}+b_{2 i}^{*} x_{2 i j}+b_{3 i}^{*} x_{3 i j}+e_{i j}$ is the random effect part of the model.

\section{Evaluation of the NRC (2001) Passage Rate Equations}

Analysis 1: Sensitivity of the Passage Rate Equations to Input Variables. Sensitivity analysis of the Kp equations to input variables (BW, DMI, ConcpDM, and NDFF) were conducted using @Risk v 4.5 (Palisade Corporation, Newfield, NY). The distribution of the input variables was described by analyzing a data set that included 232 observations with only lactating dairy cows collected from the 2001 Dairy NRC database. Descriptive statistics of the input variables in this data set are shown in Table 2. Probability distributions were fitted to the data for each variable using @Risk v 4.5 (Palisade Corp.). To select the best distribution, 3 different fit statistics ( $\chi^{2}$, Kolmogorov-Smirnov, and Anderson-Darling values) were compared. The data were assumed normally distributed if all 3 goodness-of-fit tests failed to reject the null hypothesis of normal distribution; otherwise, a probability distribution, which 
Table 2. Descriptive statistics and correlations of data from 232 lactating dairy cows ${ }^{1}$ to derive probability distributions of input variables for calculation of Kp using the NRC (2001) model $^{2}$

\begin{tabular}{lcccc}
\hline & BW $(\mathrm{kg})$ & DMI $(\mathrm{kg})$ & ConcpDM $(\%)$ & NDFF $(\%)$ \\
\hline Mean & 599 & 20.1 & 46.7 & 48.4 \\
SD & 49 & 4.1 & 14.4 & 7.5 \\
Maximum & 745 & 27.5 & 84.2 & 73.2 \\
Minimum & 430 & 6.3 & 0.0 & 31.8 \\
Spearman rank correlations & & & & \\
BW & 1.000 & 1.000 & & \\
DMI & 0.555 & 0.171 & 1.000 & 1.000 \\
ConcpDM & 0.016 & -0.165 & 0.247 & \\
NDFF & -0.169 & . & & \\
\hline
\end{tabular}

${ }^{1}$ The data set included 232 separate observations with only lactating dairy cows from the 2001 Dairy NRC database.

${ }^{2}$ ConcpDM $=$ Concentrate as a percentage of diet DM; NDFF $=$ NDF content as percentage of forage DM.

showed the best fit among 3 tests based on the ranking, was chosen. The correlations between input variables were estimated with the 232 data points using the Spearman rank-order correlation (Agresti, 2002). The correlation matrix is shown in Table 2 . The simulation was performed to obtain the distribution of Kp using @Risk v 4.5 (Palisade Corp.). The input variables needed to predict Kp for dry forage, wet forage, and concentrate in the simulation were sampled from each distribution using the Latin hypercube method. Iterations of the simulation were continued until less than $1 \%$ of convergence was achieved for all $\mathrm{Kp}$ distributions. Sensitivities of the input variables to $\mathrm{Kp}$ for dry forage, wet forage, and concentrate were analyzed by regression analysis using @Risk v 4.5 (Palisade Corp.). Three coefficients from standardized regression, and Pearson and Spearman rank correlations were used to rank the relative importance of input variables. The difference between Spearman and Pearson is that the Spearman method uses ranks instead of values (Neter et al., 1996). The Monte Carlo technique, which is a statistical simulation method, has been widely used in many fields to assess uncertainty and the risk associated with using a model (Helton and Davis, 2000; Tylutki, 2002). It involves running simulations in which inputs are assigned probability distributions and assessing the effect that the input variances have on model predictions (Frey and Patil, 2002). Sensitivity of the model to individual inputs or groups of inputs can be evaluated by a variety of techniques (Frey and Patil, 2002). Regression analysis, which has been widely used in many cases (Campolongo et al., 2000), was used in this study. Three coefficients (standardized regression, Pearson correlation, and Spearman rank correlation) were used to rank the input variables as to their relative importance. The standardized regression coefficients, when input variables are independent, provide a measure of importance based on the effect of moving each variable away from its expected value by a fixed fraction of its standard deviation while retaining the other variables at their expected values (Helton and Davis, 2000).

The correlation coefficient characterizes the effect that changing an explanatory variable by a fixed fraction of its standard deviation will have on the response variable, with this effect being measured relative to its standard deviation (Helton and Davis, 2000). The correlation coefficient can also be obtained by regressing the response variable on an explanatory variable such as the standardized regression coefficient. However, the correlation coefficient measures the strength of the linear relationship between a response variable and a given input variable without adjustment of any effect due to correlation between the input variable and the other explanatory variables. Thus, the correlation coefficient measures the correlation between a response variable and an explanatory variable irrespective of the other independent variables. It should be noted that the 2 most commonly used indexes for assessing the sensitivity of a model to input variables measure different relationships between a response variable and a predictor variable. Therefore, careful interpretations are needed.

Analysis 2: Sensitivity of Protein Outputs Using the NRC (2001) Model for Lactating Dairy Cows to Probability Distribution of Passage Rates. A sensitivity analysis of model predicted protein outputs (RDP, RUP, and MP) to the Kp equations was conducted using @Risk v 4.5 (Palisade Corp.). Probability distributions of Kp were fitted to the simulated data obtained from analysis 1 using @Risk v 4.5. Correlations were estimated among the simulated Kp using the Spearman rank method in the SAS package (SAS Institute, Inc.).

Only Kp for dry forage, wet forage, and concentrate were used for input distribution variables in this simulation. A spreadsheet was developed with the NRC (2001) equations to perform all the simulations of this study. A midlactation Holstein cow fed a diet consisting of legume hay, corn silage, corn grain, soybean meal, 
Table 3. Animal inputs used in simulations for determining the sensitivity of the NRC (2001) model in predicting protein supplies to probability distribution of $\mathrm{Kp}$

\begin{tabular}{lc}
\hline Animal inputs & Settings \\
\hline Animal type & 1 Lactating Cow \\
Age & $65 \mathrm{Month}$ \\
BW & $680 \mathrm{Kg}$ \\
BCS & 3 (1:thin to $5:$ fat $)$ \\
Age at first calving & 24 Month \\
Calving interval & 12 Month \\
Days pregnant & 0 Days \\
DIM & 90 Days \\
Lactation number & 3 \\
Breed & 4 Holstein \\
Mature weight & $680 \mathrm{~kg}$ \\
Calf birth weight & $43 \mathrm{~kg}$ \\
Milk production & $45 \mathrm{~kg} / \mathrm{d}$ \\
Milk fat & $3.5 \%$ \\
Milk protein & $3.0 \%$ total protein \\
Lactose & $4.8 \%$ \\
Temperature & $20^{\circ} \mathrm{C}$ \\
Previous temperature & $20^{\circ} \mathrm{C}$ \\
Grazing & $1 \mathrm{FALSE}$ \\
\hline
\end{tabular}

and brewers' grain was used for the simulation. The animal inputs used in this simulation are shown in Table 3, and the diet is listed in Table 4 . The Kp values were sampled from their respective distribution (Table 5) using a Latin hypercube method. Iterations of the simulation were continued until less than $1 \%$ of convergence was achieved for all output distributions.

Analysis 3: Sensitivity of Protein Outputs from the NRC (2001) Model for a Lactating Dairy Cow to Probability Distributions of Passage Rates, Feed CP, and the Kd of the Protein B Fraction. A sensitivity analysis of model predicted protein outputs (RDP, RUP, and MP) to variations in Kp for dry forage, wet forage, and concentrate, feed $\mathrm{CP}$, and the $\mathrm{Kd}$ of the protein $\mathrm{B}$ fraction of each feed ingredient was conducted
Table 5. Descriptive statistics and correlations of predicted $\mathrm{Kp}$ for dry forage, wet forage, and concentrate by input variables from 232 lactating dairy cows

\begin{tabular}{llll}
\hline & $\begin{array}{l}\text { Kp } \\
\text { dry } \\
\text { forage }\end{array}$ & $\begin{array}{l}\mathrm{Kp} \\
\text { wet } \\
\text { forage }\end{array}$ & $\begin{array}{l}\mathrm{Kp} \\
\text { concentrate }\end{array}$ \\
\hline Mean & 4.53 & 5.17 & 6.69 \\
SD & 0.33 & 0.34 & 0.77 \\
Max. & 5.70 & 6.29 & 9.22 \\
Min. & 3.42 & 3.90 & 3.61 \\
Correlations (Spearman method) & & & \\
Kp dry forage & 1.000 & & \\
Kp wet forage & 0.890 & 1.000 & \\
Kp concentrate & 0.730 & 0.922 & 1.000 \\
\hline
\end{tabular}

using @Risk v 4.5 (Palisade Corp.). The distribution of the $\mathrm{Kp}$ and the correlations among $\mathrm{Kp}$ were the same as for analysis 2 (Table 5). The CP concentrations of the feeds and the Kd of the B fraction were assumed normally distributed. The means and standard deviations were obtained from Table 15-2a in the NRC (2001) publication. No correlations were assumed to exist among the variables except among the $\mathrm{Kp}$. All animal inputs, diet composition, and simulation settings were the same as for analysis 2. Variations in RDP, RUP, MP supply and MP allowable milk were predicted with the spreadsheet version of the model as described previously.

\section{RESULTS AND DISCUSSION}

\section{Development of the NRC (2001) Passage Rate Equations}

An initial analysis of the database resulted in the same equations as reported in NRC (2001) except that the sign of the regression coefficient for concentrate

Table 4. Feed inputs used in simulations for determining the sensitivity of the NRC (2001) model in predicting protein supplies to probability distributions of $\mathrm{Kp}$

\begin{tabular}{|c|c|c|c|c|c|c|}
\hline Feed name & $\begin{array}{l}\mathrm{DMI}, \\
\mathrm{kg} / \mathrm{d}\end{array}$ & $\begin{array}{l}\mathrm{CP}, \\
\mathrm{g} / \mathrm{d}\end{array}$ & $\begin{array}{l}\mathrm{RUP},{ }^{1} \\
{ }^{3}\end{array}$ & $\begin{array}{l}\mathrm{RDP},{ }^{2} \\
\%\end{array}$ & $\begin{array}{l}\mathrm{Kd},{ }^{4} \\
\% / \mathrm{h}\end{array}$ & $\begin{array}{l}\mathrm{Kp},{ }^{5} \\
\% / \mathrm{h}\end{array}$ \\
\hline Legume forage hay, immature & 4.90 & 1,117 & 11.5 & 32.8 & 18.04 & 4.53 \\
\hline Corn silage, normal & 8.00 & 704 & 15.1 & 16.2 & 4.41 & 5.17 \\
\hline Corn grain, ground, dry & 9.30 & 874 & 24.3 & 16.9 & 4.95 & 6.70 \\
\hline Soybean meal, solvent $48 \% \mathrm{CP}$ & 2.20 & 1,184 & 29.4 & 24.9 & 7.51 & 6.70 \\
\hline Brewers grains, dried & 2.00 & 584 & 19.8 & 9.3 & 4.70 & 6.70 \\
\hline Monosodium phosphate $\left(\mathrm{H}_{2} \mathrm{O}\right)$ & 0.06 & & & & & \\
\hline Salt & 0.15 & & & & & \\
\hline Vitamin premix & 0.36 & & & & & \\
\hline Totals & 26.97 & 4,463 & 100.0 & 100.0 & & \\
\hline
\end{tabular}

${ }^{1}$ Calculated by $\mathrm{CP} \times \mathrm{Kp}$ over the sum of $\mathrm{Kd}$ and $\mathrm{Kp}$.

${ }^{2}$ Calculated by $\mathrm{CP} \times \mathrm{Kd}$ over the sum of $\mathrm{Kd}$ and $\mathrm{Kp}$.

${ }^{3}$ Values are a percentage of total RUP in diet.

${ }^{4}$ Fractional rate of digestion in the rumen of the B fraction of CP.

${ }^{5}$ Fractional rate of passage out of the rumen. 


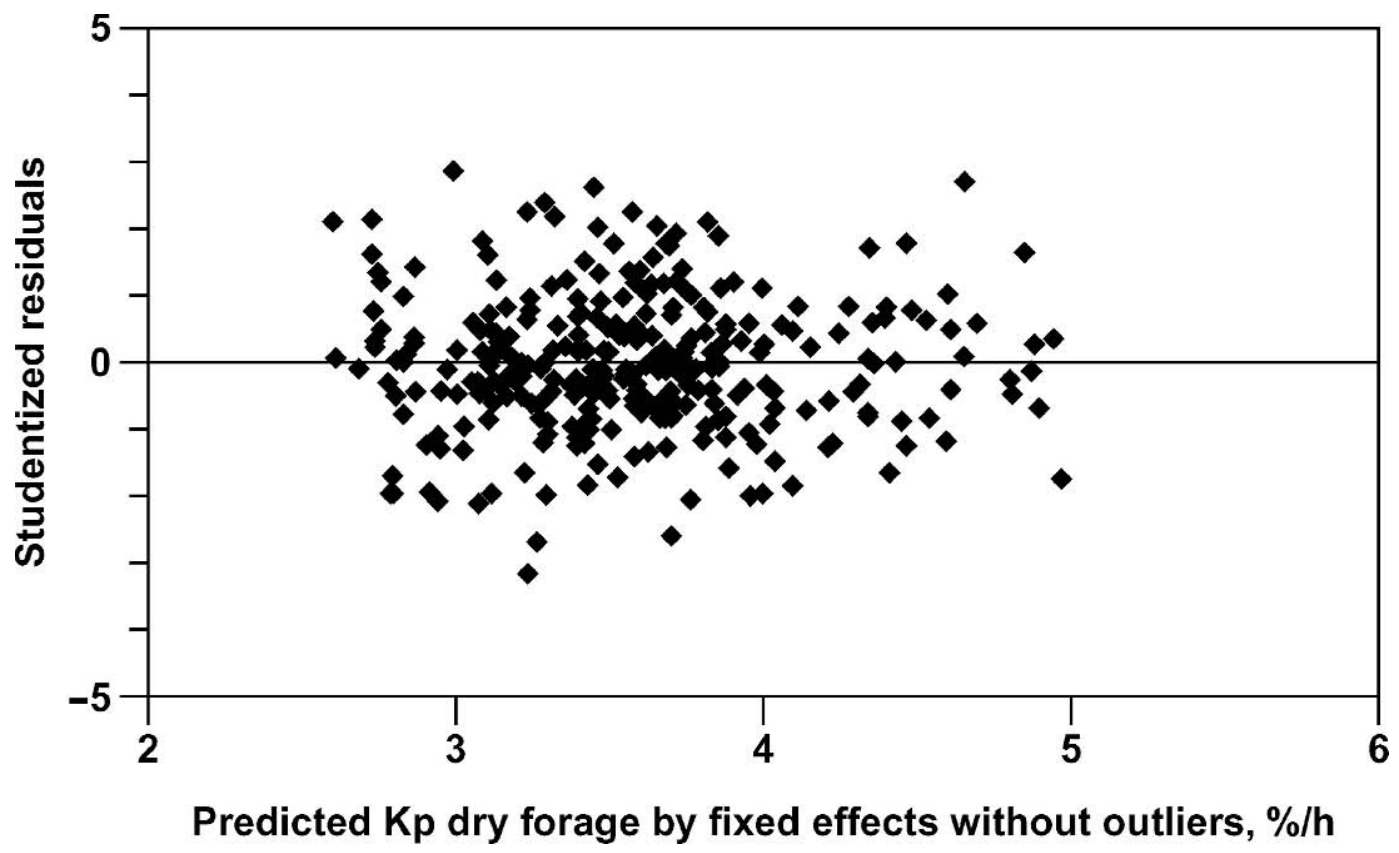

Figure 1. Studentized residual plot of predicted Kp for dry forage without outliers. Studentized residuals were calculated by subtracting predicted $\mathrm{Kp}$ by fixed effects from observed $\mathrm{Kp}$ adjusted for study effect and then dividing by square root of mean squared error (MSE).

content in dietary DM in the equation to estimate $\mathrm{Kp}$ of dry forage was found to be a plus and not a minus (+0.007 instead of -0.007). This typographical error may cause a $15 \%$ lower prediction of $\mathrm{Kp}$ for dry forage. However, its effect on model prediction of MP supply and MP allowable milk was less than $1 \%$ (data not shown). The corrected passage rate equation for dry forages and the other 2 equations to estimate rate of passage of undigested feed out of the rumen are shown below. The parameter estimates are the solution for each fixed effect:

Kp for dry forage $=3.362( \pm 0.263)+0.479( \pm 0.052)$

$$
\begin{aligned}
& \text { DMIpBW - } 0.017( \pm 0.004) \text { NDFF } \\
& +0.007( \pm 0.002) \text { ConcpDM; }
\end{aligned}
$$

$\mathrm{Kp}$ for wet forage $=3.054( \pm 0.393)$

$$
+0.614( \pm 0.126) \text { DMIpBW; }
$$

$\mathrm{Kp}$ for concentrate $=2.904( \pm 0.516)+1.375( \pm 0.177)$

$$
\text { DMIpBW - } 0.020 \text { ( } \pm \text { 0.006) ConcpDM; }
$$

where DMIpBW = DMI as a percentage of $\mathrm{BW}$, ConcpDM = concentrate content of the diet, $\% \mathrm{DM}$, and $\mathrm{NDFF}=\mathrm{NDF}$ of forage feedstuff, \% DM.

As shown in Table 1, the database used to develop the equations had wide ranges in DMI, BW, and DMIpBW. Therefore, these equations are expected to cover a wide range of production situations. The passage rate equa- tions for dry forages (corrected equation), wet forages and concentrates explain 87,86 , and $91 \%$, respectively of the variation in measured passage rates in the database used in equation development, when the observations were adjusted for random study effect. Figures 1 , 3 , and 5 show the studentized residual plots of the observed and predicted $\mathrm{Kp}$ by fixed effects of the equations. The plots indicated there was no apparent bias and the regression models seemed to be appropriate.

To evaluate the effect of omitting outliers, the data that were originally treated as outliers and removed in the development of equations (25,5, and 1 observations in dry forage, wet forage, and concentrates, respectively) were added back to the database and the parameters for the variables were reestimated. The equations are shown below, and the residual plots of the observed and predicted $\mathrm{Kp}$ by fixed effects of the equations are shown in Figures 2, 4, and 6.

Kp for dry forage $=4.542( \pm 0.321)+0.485( \pm 0.064)$

$$
\begin{aligned}
& \text { DMIpBW }-0.035( \pm 0.004) \mathrm{NDFF} \\
+ & 0.006( \pm 0.002) \text { ConcpDM }(\mathrm{n}=344) ;
\end{aligned}
$$

Kp for wet forage $=2.948( \pm 0.418)$

$$
+0.655( \pm 0.134) \text { DMIpBW }(\mathrm{n}=68) \text {; }
$$

Kp for concentrate $=3.205( \pm 0.567)+1.325( \pm 0.178)$

DMIpBW - $0.023( \pm 0.006)$ ConcpDM $(\mathrm{n}=140)$; 


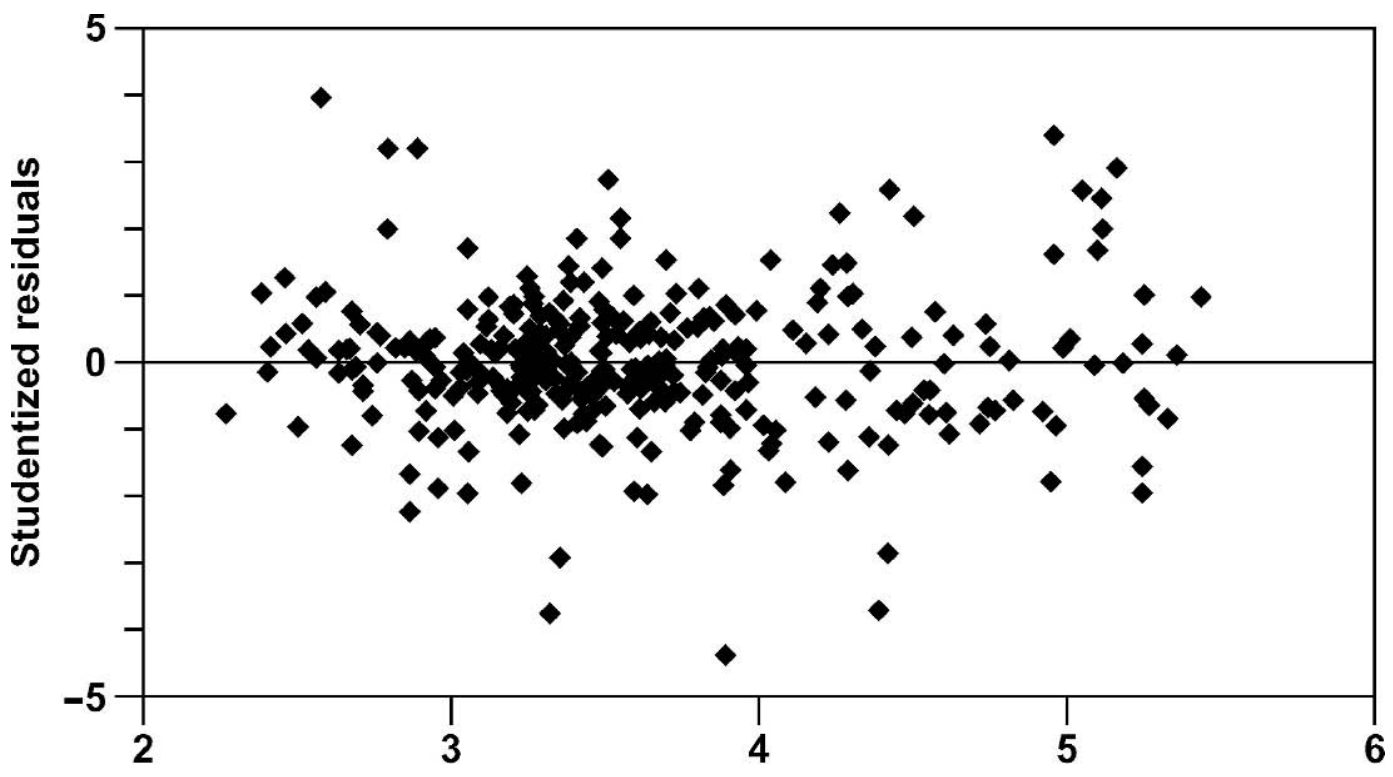

Predicted Kp dry forage by fixed effects with outliers, \%/h

Figure 2. Studentized residual plot of predicted Kp for dry forage with outliers. Studentized residuals were calculated by subtracting predicted $\mathrm{Kp}$ by fixed effects from observed $\mathrm{Kp}$ adjusted for study effect and then dividing by square root of mean squared error (MSE).

where DMIpBW = DMI as a percentage of $\mathrm{BW}$, ConcpDM = concentrate content of the diet, $\% \mathrm{DM}$, and $\mathrm{NDFF}=\mathrm{NDF}$ of forage feedstuff, \% DM.

Simple 2-sample tests were conducted to see if the estimates for the parameters computed without or with outliers were significantly different, assuming that the estimates were normally distributed with the mean and the standard errors of the estimates. Because omitting data points was not substantial in the equations of $\mathrm{Kp}$ for wet forages and concentrates, the parameter esti-

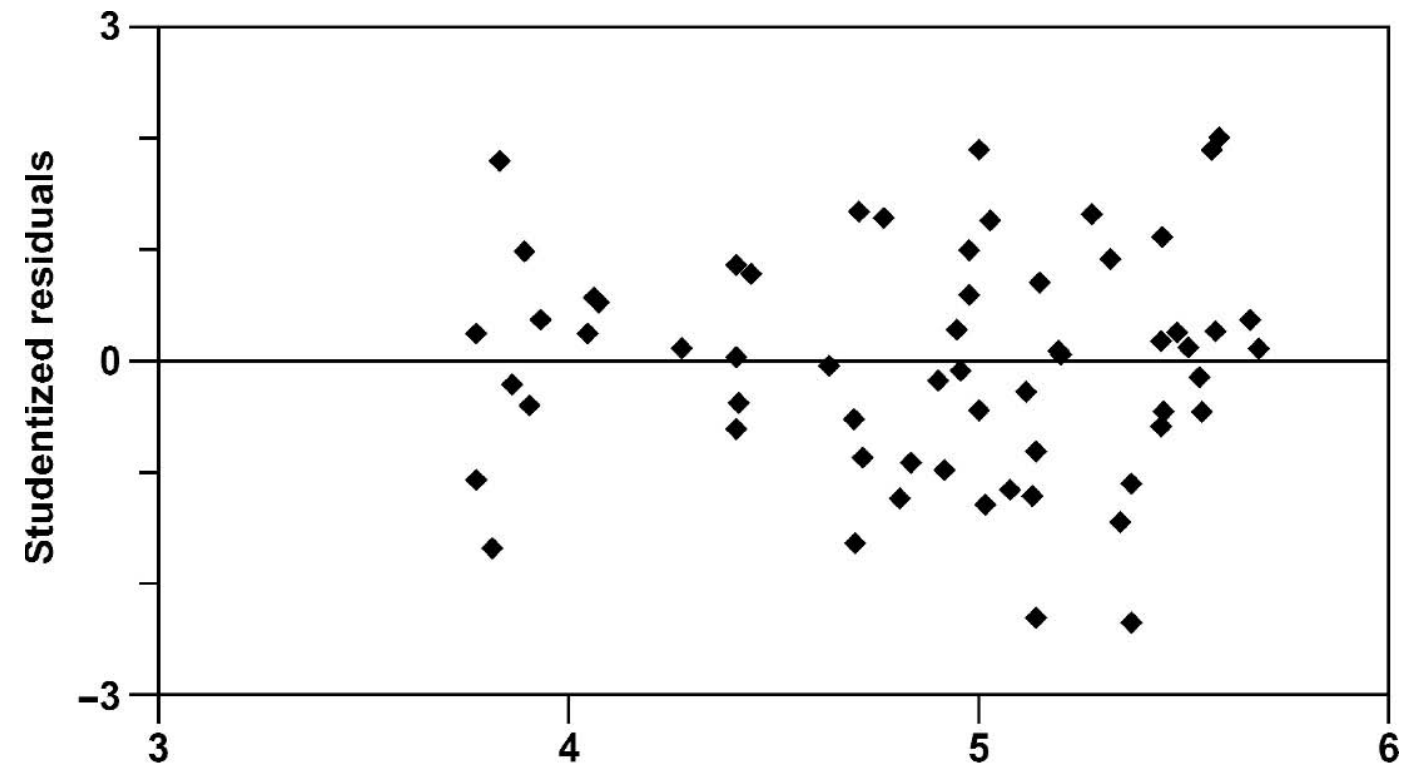

Predicted Kp wet forage by fixed effects without outliers, \%/h

Figure 3. Studentized residual plot of predicted Kp for wet forage without outliers. Studentized residuals were calculated by subtracting predicted $\mathrm{Kp}$ by fixed effects from observed $\mathrm{Kp}$ adjusted for study effect and then dividing by square root of mean squared error (MSE). 


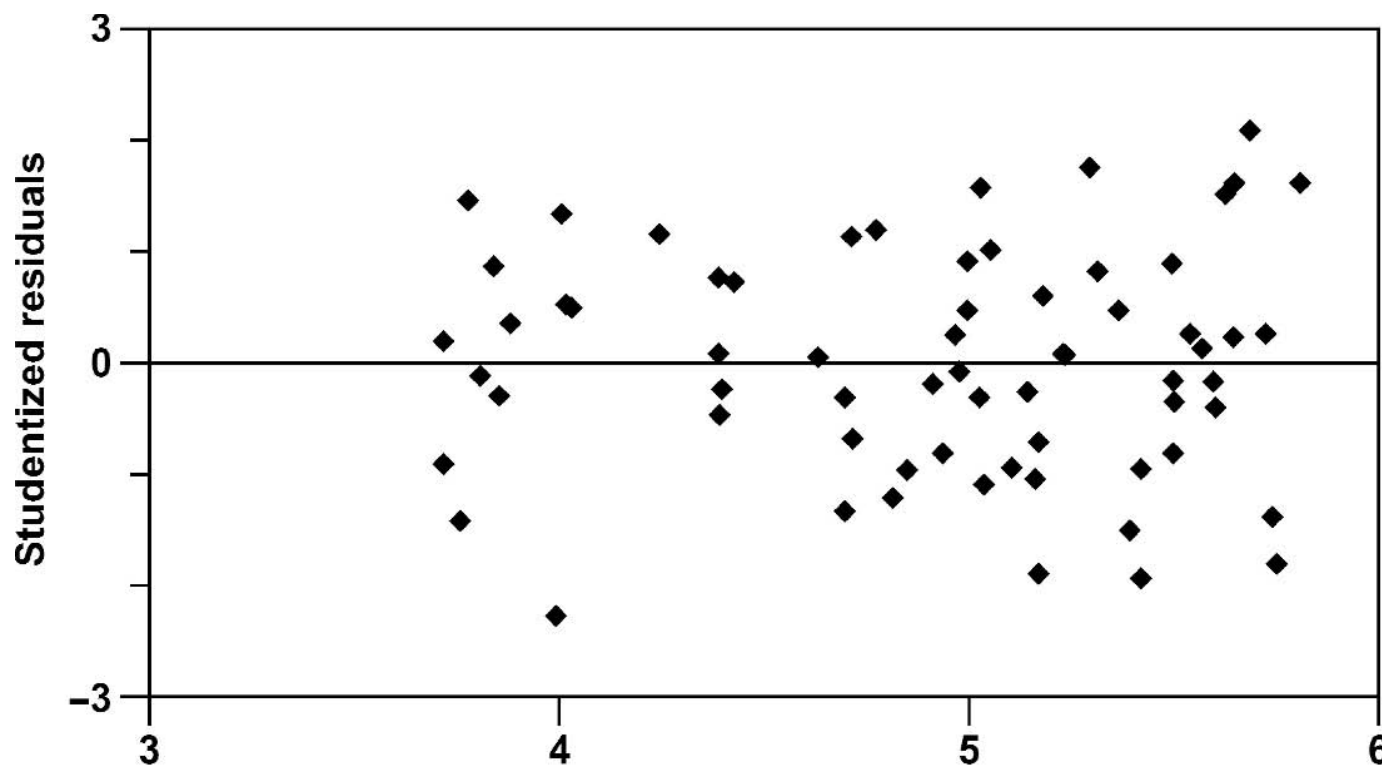

Predicted Kp wet forage by fixed effects with outliers, \%/h

Figure 4. Studentized residual plot of predicted $\mathrm{Kp}$ for wet forage with outliers. Studentized residuals were calculated by subtracting predicted $\mathrm{Kp}$ by fixed effects from observed $\mathrm{Kp}$ adjusted for study effect and then dividing by square root of mean squared error (MSE).

mates did not significantly differ $(P>0.05)$, and the studentized residual plots show similar patterns (Figures $3,4,5$, and 6 ); there are some extreme values in Figures 4 and 6. However, there were significant changes in the Kp equation for dry forages when the outliers were added. Differences in the estimates of intercept and NDFF in the equation of Kp dry forage were highly significant $(P<0.01)$. Although there are

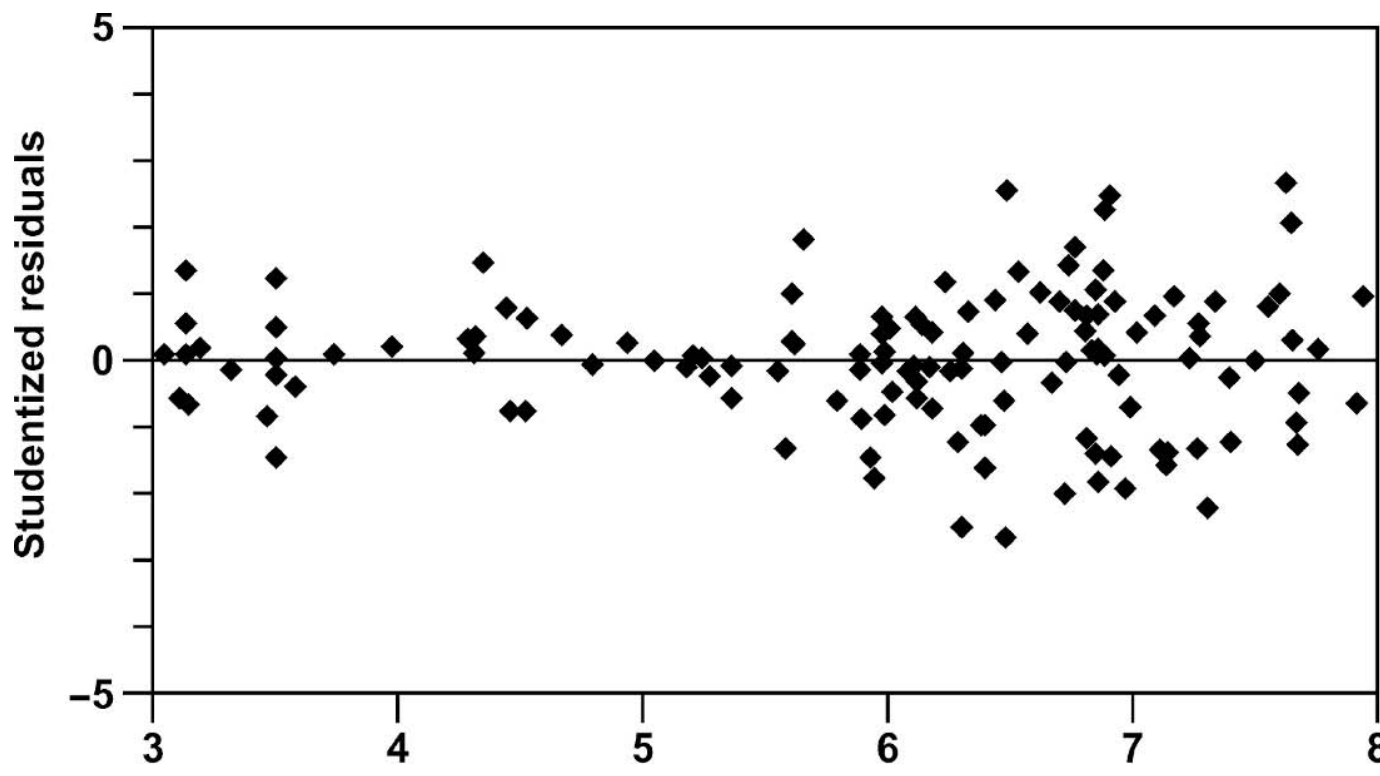

Predicted Kp concentrate by fixed effects without outliers, \%/h

Figure 5. Studentized residual plot of predicted Kp for concentrates without outliers. Studentized residuals were calculated by subtracting predicted Kp by fixed effects from observed Kp adjusted for study effect and then dividing by square root of mean squared error (MSE). 


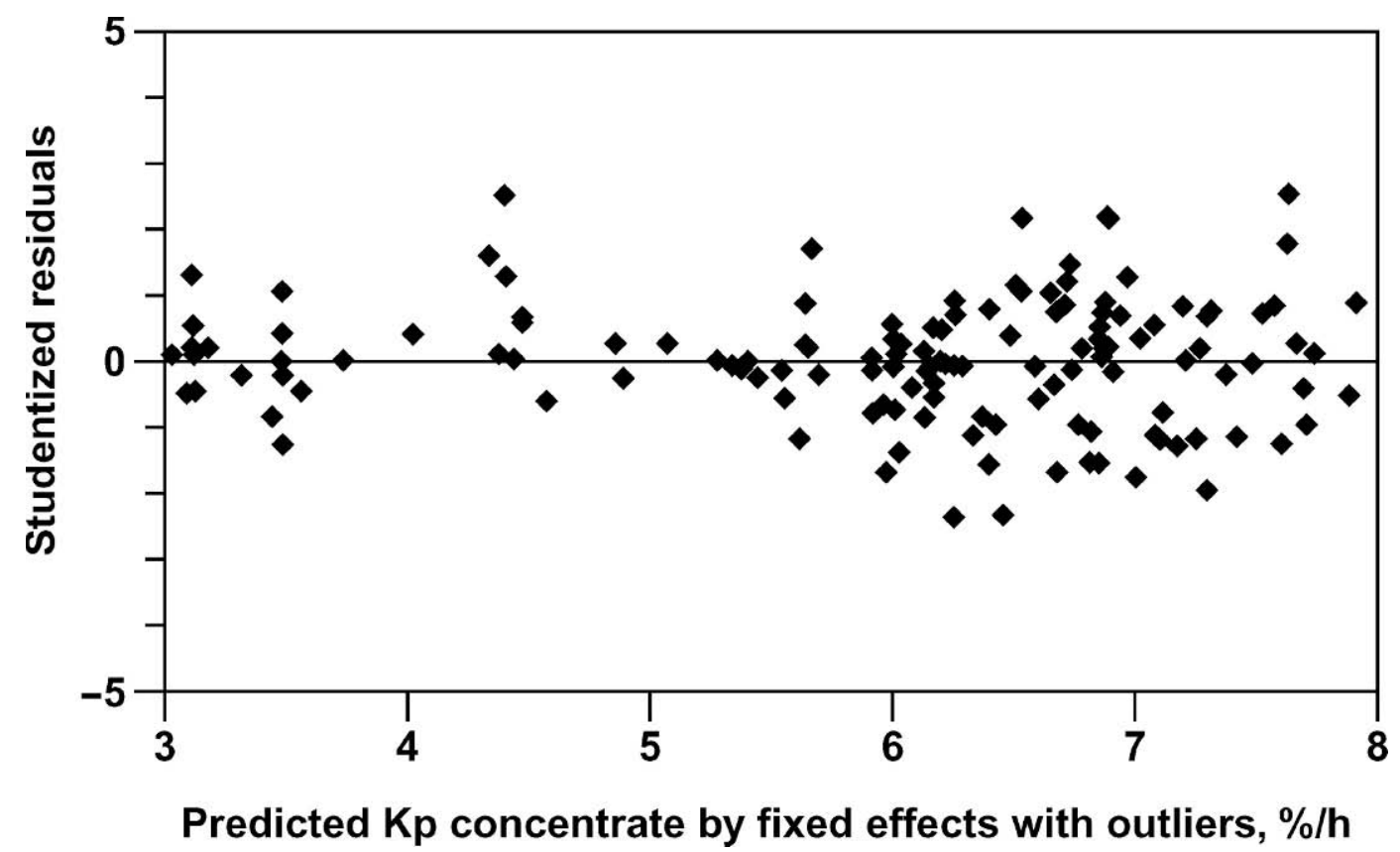

Figure 6. Studentized residual plot of predicted Kp for concentrates with outliers. Studentized residuals were calculated by subtracting predicted $\mathrm{Kp}$ by fixed effects from observed $\mathrm{Kp}$ adjusted for study effect and then dividing by square root of mean squared error (MSE).

several techniques available to detect outliers and influential points, justification for discarding outliers is controversial and one should be careful in eliminating data points in a regression analysis (Neter et al., 1996). Discarding outliers may overstate the precision of a model. When the outliers were included in the data set, the Kp equation for dry forage was able to explain $80 \%$ of the variation in measured passage rates in the database, when the observations were adjusted for random study effect. Meta-analysis is an analysis of data, and thus, a mean of observations is treated as an experimental unit or sometimes as a sampling unit even though they are treatment means (Sutton, 2000), and outliers can be eliminated from the database if it is obvious that they are erroneous measurements. Because there was no direct evidence that the outliers in the database represent errors, this analysis indicates that elimination of outliers in development of Kp equations by NRC (2001) was not justified.

To evaluate the difference in predictions between the Kp dry forage equation with and without outliers, a simple simulation was conducted with the similar method described for our first analysis. The original equation underestimates $\mathrm{Kp}$ dry forage by $0.28 \% / \mathrm{h}$ on average compared with the equation with outliers (Figure 7).

There was considerable heterogeneity among the different studies in the database, including procedure, type of marker used, concentration of marker, dose and data collection site, mathematical model used to fit the curve, and technician conducting the experiment. It is also understood that observations within a given study are more correlated than observations across studies, and that accuracy of measurements within and across studies is different (St-Pierre, 2001). Ignoring the blocking effect of studies and heterogeneity of variances results in estimates of the parameters in the regression equation that contain considerable bias (St-Pierre, 2001). Application of meta-analysis to remove this bias can reduce the effect of random error and so produce more reliable and precise estimates when pooling all the relevant studies (Sutton, 2000).

\section{Evaluation of the NRC (2001) Passage Rate Equations}

Analysis 1: Sensitivity of the Passage Rate Equations to Input Variables. The distributions of input variables for the analysis were obtained from a reconstructed data set from 232 lactating dairy cows (Table 2 ). Mean ( \pm standard deviation) values of BW, DMI, ConcpDM, and NDFF of the data set were $599( \pm 49)$ $\mathrm{kg}, 20.1( \pm 4.1) \mathrm{kg}, 46.7( \pm 14.4) \% \mathrm{DM}$, and $48.4( \pm 7.5)$ $\% \mathrm{DM}$, respectively. Body weights and DMI were highly correlated; the Spearman rank correlation coefficient was 0.56 . The other variables appeared to be independent of each other. Table 5 shows the means and standard deviations for the predicted $\mathrm{Kp}$ values of the ani- 


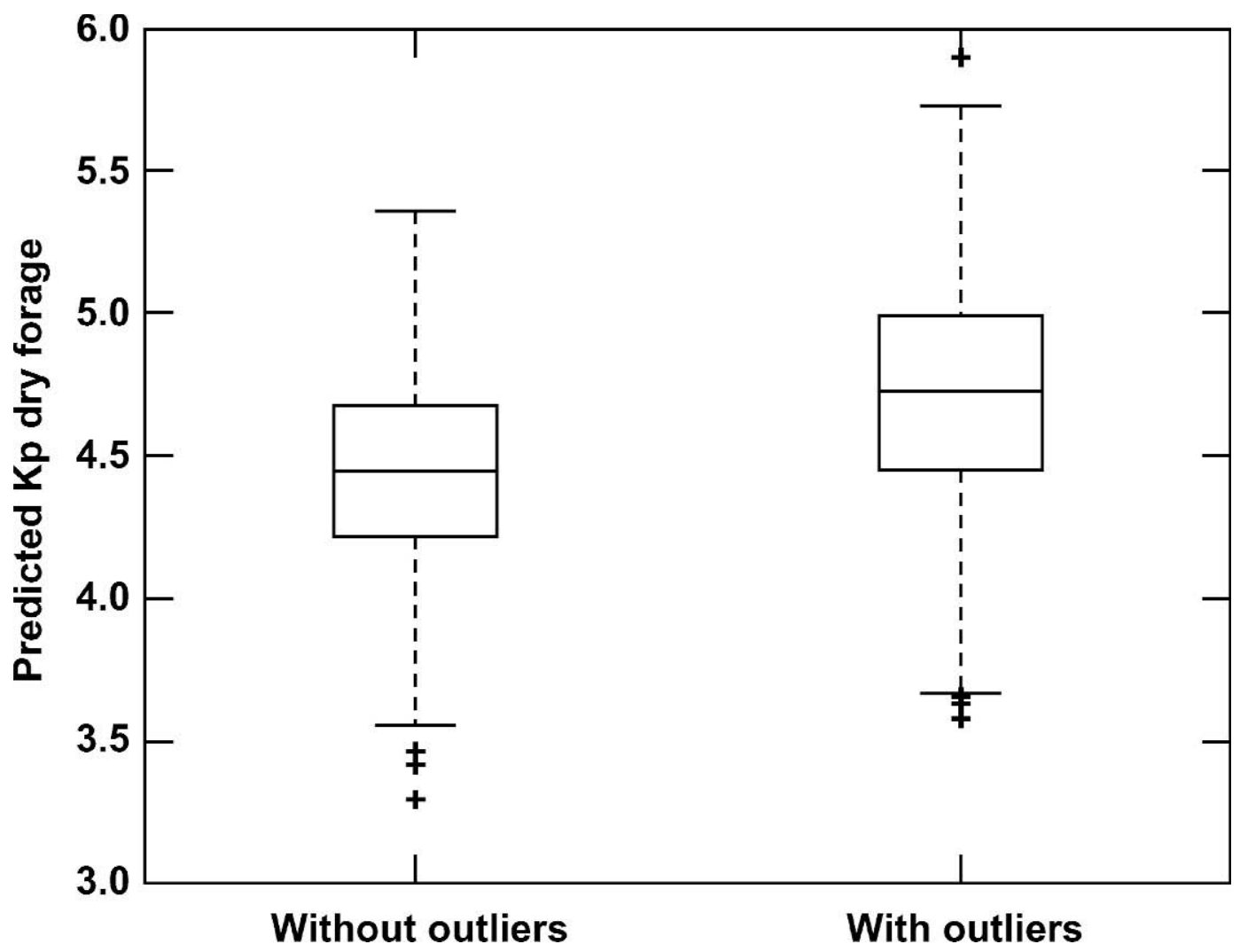

Figure 7. Box plots for the variability in predicted Kp for dry forages by the equations developed with or without outliers. The middle line in the box represents the median, the upper and lower areas of the center box indicate the 75th and 25th percentiles, the whiskers extending from each end of the box show the extent of the rest of the data, and the crosses beyond the ends of the whiskers represent extreme values.

mals in the data set. The predicted Kp were highly correlated among themselves. Using the Spearman rank method, which is a nonparametric rank correlation procedure (Neter et al., 1996), the highest correlation (0.922) was between the $\mathrm{Kp}$ for wet forage and the $\mathrm{Kp}$ for concentrate. The correlation coefficients of the $\mathrm{Kp}$ for dry forage with the $\mathrm{Kp}$ of wet forage and concentrate were 0.89 and 0.73 , respectively. These high correlations between passage rates for the 3 feed types are because all equations have DMI as percentage BW as the most effective predictor variable. The coefficients for sensitivity of the input variables to $\mathrm{Kp}$ for dry forage, wet forage and concentrate (standardized regression, and Pearson and Spearman correlations) and their ranking are shown in Table 6 .

Our Monte Carlo analysis indicated that if DMI increases from 20.1 (Table 2) to $24.2 \mathrm{~kg} / \mathrm{d}$ while the other variables remain at their mean values, the Kp for dry forage increases 0.948 times its standard deviation of $0.33 \% / \mathrm{h}$, or from 4.53 to $4.84 \% / \mathrm{h}$ (a $7 \%$ increase), and the $\mathrm{Kp}$ for concentrate increases 1.156 times its standard deviation of $0.77 \% / \mathrm{h}$, or from 6.69 to $7.58 \% / \mathrm{h}$ (a
$13 \%$ increase). Thus, based on our analysis, the Kp for concentrate was more sensitive to DMI than the Kp for dry forage. These predicted changes in $\mathrm{Kp}$ values may not be correct due to the positive correlation between DMI and BW. However, the trends should be the same.

The results of the sensitivity analysis indicated that all 3 equations are much more sensitive to DMI than to any other inputs and the relationship was positive with all 3 passage rates. Assuming steady-state conditions, fractional rate of passage can be calculated by dividing rate of intake $(\mathrm{kg} / \mathrm{h})$ by pool size of rumen contents (kg). Fractional rate of passage, therefore, is linearly related to intake when pool size of rumen contents is constant. However, an increase in feed intake from a low level to a higher level does not consistently increase digesta flow if there is a compensatory increase in ruminal fill (Owens and Goetsch, 1986). When rumen capacity is reached, a faster intake causes a faster rate of passage proportional to level of intake. Gastrointestinal capacity is linearly related to BW (Van Soest, 1994), and thus DMI expressed in proportion to animal BW was the most important factor for determining the rate 
Table 6. Sensitivity of predicted passage rates to the input variables of the equations (the number in parentheses is the relative rank among the 4 variables)

\begin{tabular}{|c|c|c|c|c|}
\hline $\mathrm{Kp}$ for & $\begin{array}{l}\text { Input } \\
\text { variables }^{1}\end{array}$ & $\begin{array}{l}\text { Standard } \\
\text { regression }\end{array}$ & $\begin{array}{l}\text { Spearman } \\
\text { correlation }\end{array}$ & $\begin{array}{l}\text { Pearson } \\
\text { correlation }\end{array}$ \\
\hline Dry forage & $\begin{array}{l}\text { BW } \\
\text { DMI } \\
\text { ConcpDM } \\
\text { NDFF }\end{array}$ & $\begin{array}{r}-0.412(2) \\
0.948(1) \\
0.280(4) \\
-0.389(3)\end{array}$ & $\begin{array}{r}0.156(4) \\
0.820(1) \\
0.322(3) \\
-0.426(2)\end{array}$ & $\begin{array}{r}0.158(4) \\
0.841(1) \\
0.326(3) \\
-0.441(2)\end{array}$ \\
\hline Wet forage & $\begin{array}{l}\text { BW } \\
\text { DMI } \\
\text { ConcpDM } \\
\text { NDFF }\end{array}$ & $\begin{array}{r}-0.506(2) \\
1.165(1) \\
0.000(3) \\
0.000(3)\end{array}$ & $\begin{array}{r}0.094(4) \\
0.875(1) \\
0.151(2) \\
-0.119(3)\end{array}$ & $\begin{array}{r}0.107(4) \\
0.898(1) \\
0.147(2) \\
-0.134(3)\end{array}$ \\
\hline Concentrate & $\begin{array}{l}\text { BW } \\
\text { DMI } \\
\text { ConcpDM } \\
\text { NDFF }\end{array}$ & $\begin{array}{r}-0.502(2) \\
1.156(1) \\
-0.343(3) \\
0.000(4)\end{array}$ & $\begin{array}{r}0.081(4) \\
0.810(1) \\
-0.187(2) \\
-0.183(3)\end{array}$ & $\begin{array}{r}0.104(4) \\
0.847(1) \\
-0.195(3) \\
-0.198(2)\end{array}$ \\
\hline
\end{tabular}

${ }^{1} \mathrm{ConcpDM}=$ Concentrate as a percentage of diet DM; NDFF = NDF content as percentage of forage DM.

of passage of digesta out of the rumen. However, the relative importance of BW alone was not clear, based on the sensitivity analysis with different regression coefficients. The Spearman rank and the Pearson correlation methods indicated that BW was positive but was the least influential predictor among the input variables in estimating all 3 passage rates. In contrast, BW was negative and was the second most important variable based on the standardized regression coefficient. Even though the standardized regression coefficient indicated that BW had a strongly negative effect on $\mathrm{Kp}$, the correlation coefficient implied that there is no linear relationship between $\mathrm{BW}$ and $\mathrm{Kp}$. This is because the standardized regression controls all variables but the one of interest whereas correlation does not. Dry matter intake is highly correlated with passage rate but BW is not, even though DMI and BW are highly correlated. These results are consistent with correlation analysis of the observations in the original database. The Pearson correlation coefficient between the Kp for dry forage and DMI was 0.45 , whereas the coefficient between the $\mathrm{Kp}$ for dry forage and BW was 0.13 . The correlation coefficient of the Kp for wet forage with DMI was 0.76 and with BW it was 0.57 . The Kp for concentrate was correlated with DMI and BW with coefficients of 0.66 and 0.35 , respectively. We concluded that $\mathrm{BW}$ alone is not highly correlated with passage rates of undigested feed even though it is a significant and important variable in predicting rate of passage.

The results of this sensitivity analysis indicated that accurate determination of DMI is the most important factor for accurate prediction of feed passage out of the rumen in the NRC (2001) model, and that DMI as a percentage of $\mathrm{BW}$ has a positive linear relationship with all 3 passage rates. Degree of sensitivity to DMI, however, is different for the $3 \mathrm{Kp}$ equations. The effect of increases in DMI on Kp was the highest for concentrate, intermediate for wet forage, and lowest in dry forage. This is consistent with the finding that as feed intake increases, fractional passage rate of concentrate increased more than that of roughage (Owens and Goetsch, 1986). Concentrate particles normally have a smaller particle size and a higher specific gravity than forages (Offer and Dixon, 2000), which increases rate of passage out of the rumen.

The NDF content of forage was a significant predictor of passage rates for dry forage in the NRC (2001) model and was shown in this study to be negatively correlated when DMIpBW and ConcpDM were already in the model. Welch (1982) observed that consumption of coarse NDF increases rumination time and thus, decreases rate of passage of forage out of the rumen. In the current equation, the degree of decrease, however, was so low that a $10 \%$ increase in NDF content of forage decreased Kp for dry forage only $0.17 \%$. Content of concentrate in diet DM had a negative effect on concentrate passage rate and a small but positive effect on dry forage passage rate. Decreasing concentrates in diet DM increases passage rates of concentrates (Owens and Goetsch, 1986; Offer and Dixon, 2000) and this is due to increased contraction of the omasum (Grovum, 1986) by increased intake of forages. However, the effect of increased intake of concentrate proportions on passage rate of dry forage seemed to be dependent on level of intake (Offer and Dixon, 2000). Colucci (1990) reported negative effects of increased concentrate proportions on passage rates at lower levels of intake. However, the effect became nonsignificant at higher levels of intake. In our study, concentrate content in the diet had a positive correlation with Kp dry forage even though the effect was small and biologically negligible. Dry matter intake as a percentage of BW was the only statistically 
Table 7. Effects of variation in passage rate on predicted protein supply in the 2001 Dairy NRC model $(\text { analysis } 2)^{1}$

\begin{tabular}{lcrrrrr}
\hline Protein values & Mean & SD & $5 \%$ tile & $95 \%$ tile & $95 \%-5 \%$ & $\%$ Change \\
\hline RDP supplied (g) & 2,839 & 67 & 2,736 & 2,951 & 215 & 7.6 \\
RDP balance (g) & 188 & 67 & 85 & 300 & 215 & - \\
RUP required (g) & 1,648 & 3 & 1,644 & 1,653 & 9 & 0.5 \\
RUP supplied (g) & 1,624 & 67 & 1,512 & 1,727 & 215 & 13.2 \\
RUP balance (g) & -24 & 70 & -141 & 83 & 224 & - \\
Microbial CP (g) & 2,253 & 1 & 2,253 & 2,253 & 0 & - \\
MP from bacteria (g) & 1,442 & 1 & 1,442 & 1,442 & 0 & - \\
MP from RUP (g) & 1,367 & 59 & 1,269 & 1,457 & 188 & 13.8 \\
MP supplied (g) & 2,937 & 59 & 2,839 & 3,026 & 188 & 6.4 \\
MP balance (g) & -20 & 59 & -118 & 70 & 188 & - \\
Total EAA (g) & 1,572 & 24 & 1,531 & 1,609 & 78 & 5.0 \\
MP allowable milk (kg) & 44.6 & 1.3 & 42.4 & 46.6 & 4 & 9.0 \\
\hline
\end{tabular}

${ }^{1} 5 \%$ tile $=5$ th percentile; $95 \%$ tile $=95$ th percentile; $95 \%-5 \%=$ difference between 95 th and 5 th percentile; and $\%$ Change $=(95 \%$ tile $-5 \%$ tile $) /$ Mean $\times 100$.

significant variable in predicting Kp of wet forage. Neither NDF content in forage nor concentrate content in diet had a significant association with fractional rate of passage of wet forage.

Analysis 2: Sensitivity of Protein Outputs in the NRC Model to Probability Distribution of Passage Rates. Variations in protein outputs of the NRC (2001) model due to variation in Kp are shown in Table 7. The difference in predicted protein supplies between the 5 th and 95th percentiles are presented to show a possible change of the values within a $90 \%$ confidence interval. The difference between them was also used to calculate the possible change within the $90 \%$ confidence interval, expressed as a percentage of the mean. As described previously, the ration used for this study consisted of legume hay, corn silage, ground corn, soybean meal, and brewers' grains. These feeds were selected because they are typical feed ingredients for lactating dairy cow diets in North America (Mowrey and Spain, 1999). As Kp increased, RDP supply decreased and RUP supply increased. Random variation in $\mathrm{Kp}$ caused $215 \mathrm{~g}$ of variation in predicted RDP and RUP supplies and RDP balance, with a $90 \%$ probability. There was $188 \mathrm{~g}$ of variation in predicted MP supplies from RUP due to the variability of $\mathrm{Kp}$. Consequently, MP allowable milk varied $4 \mathrm{~kg}$ within a $90 \%$ confidence interval. Predicted supplies of MP from bacteria were not affected by variability of Kp. This is because predicted RDP supplies were adequate in all cases and microbial CP (MCP) production in the NRC (2001) model is independent of rate of passage or digestion in such cases. In the NRC (2001) model, MCP synthesis is calculated from total digestible nutrient (TDN) intake $(0.13 \times$ TDN) as long as the $\mathrm{RDP}$ requirement is met. If the $\mathrm{RDP}$ requirement is not met, then MCP yield is calculated as 0.85 times the predicted RDP supply.

As indicated above, the only effect of the passage rate equations in the NRC (2001) model is to partition the amount of CP in feeds between RDP and RUP. However, higher fractional passage rates of solids (Kennedy and Doyle, 1993) and liquids (Evans, 1981a) have been shown to be associated with more efficient production of MCP per unit of DM digested, presumably because the efficiency of microbial protein synthesis is enhanced through a reduction of microbial maintenance requirements with higher turnover rates (Evans, 1981a). This effect cannot be accounted for by the NRC (2001) model.

Table 8 shows the results of the sensitivity of protein balances to $\mathrm{Kp}$ of each of the 3 passage rate equations. The standardized regression and correlation coefficients indicate $\mathrm{Kp}$ of concentrate was the most important variable in predicting protein supply in this simulation. Although the correlation coefficients indicated that the $\mathrm{Kp}$ for dry forage and wet forage had

Table 8. Relative importance of passage rate equations in predicting protein balance in the 2001 Dairy NRC model (analysis 2)

\begin{tabular}{llll}
\hline Protein values & Kp $^{1}$ & $\begin{array}{l}\text { Regression } \\
\text { coefficient }^{1}\end{array}$ & $\begin{array}{l}\text { Correlation } \\
\text { coefficient }\end{array}$ \\
\hline RDP balance & Kpconc & -0.884 & -0.995 \\
& Kpdry & -0.104 & -0.774 \\
RUP balance & Kpwet & -0.033 & -0.944 \\
& Kpconc & 0.907 & 0.997 \\
& Kpdry & 0.092 & 0.764 \\
Microbial CP & Kpwet & 0.017 & 0.940 \\
& Kpconc & -0.150 & -0.074 \\
& Kpdry & 0.000 & -0.074 \\
MP balance & Kpwet & 0.000 & -0.074 \\
& Kpconc & 0.906 & 0.997 \\
Total EAA & Kpdry & 0.092 & 0.764 \\
& Kpwet & 0.019 & 0.940 \\
KP allowable milk & Kpconc & 0.899 & 0.996 \\
& Kpdry & 0.106 & 0.770 \\
& Kpwet & 0.015 & 0.942 \\
& Kpdry & 0.906 & 0.997 \\
& Kpwet & 0.092 & 0.764 \\
\hline
\end{tabular}

${ }^{1} \mathrm{Kpconc}$, Kpdry, and Kpwet are Kp concentrate, Kp dry forage, and $\mathrm{Kp}$ wet forage, respectively. 
Table 9. Effect of variation in feed CP, Kd of protein B fraction, and passage rate on predicted protein supply in the 2001 Dairy NRC model (analysis 3)

\begin{tabular}{|c|c|c|c|c|c|c|c|}
\hline & Mean & $\mathrm{SD}$ & Median & $5 \%$ & $95 \%$ & $95 \%-5 \%$ & $\%$ Change $^{1}$ \\
\hline \multicolumn{8}{|l|}{ Inputs $(\% \mathrm{DM}$ or $\% / \mathrm{h})$} \\
\hline Legume hay_CP ${ }^{2}$ & 22.80 & 2.10 & 22.81 & 19.35 & 26.26 & 6.92 & 30.3 \\
\hline Legume hay_Kd ${ }^{3}$ & 18.05 & 7.49 & 17.93 & 5.75 & 30.64 & 24.89 & 137.9 \\
\hline Corn silage_CP & 8.79 & 1.20 & 8.80 & 6.82 & 10.76 & 3.94 & 44.8 \\
\hline Corn silage_Kd & 4.41 & 1.49 & 4.40 & 1.97 & 6.89 & 4.92 & 111.4 \\
\hline Corn_CP & 9.40 & 1.30 & 9.40 & 7.24 & 11.53 & 4.29 & 45.7 \\
\hline Corn_Kd & 4.96 & 1.94 & 4.93 & 1.79 & 8.21 & 6.43 & 129.7 \\
\hline SBM_CP & 53.80 & 2.10 & 53.80 & 50.34 & 57.24 & 6.90 & 12.8 \\
\hline SBM_Kd & 7.51 & 2.39 & 7.51 & 3.56 & 11.45 & 7.89 & 105.0 \\
\hline Brewers grain_CP & 29.22 & 4.01 & 29.21 & 22.65 & 35.83 & 13.18 & 45.1 \\
\hline Brewers grain_Kd & 4.71 & 1.39 & 4.71 & 2.42 & 7.01 & 4.59 & 97.4 \\
\hline Kp for dry forage & 4.53 & 0.33 & 4.53 & 3.99 & 5.06 & 1.07 & 23.6 \\
\hline $\mathrm{Kp}$ for wet forage & 5.17 & 0.35 & 5.17 & 4.61 & 5.74 & 1.12 & 21.7 \\
\hline Kp for concentrate & 6.70 & 0.78 & 6.69 & 5.43 & 7.96 & 2.54 & 37.9 \\
\hline \multicolumn{8}{|l|}{ Outputs $(\mathrm{g})$} \\
\hline Microbial CP & 2,229 & 61 & 2,253 & 2,086 & 2,253 & 168 & 7.5 \\
\hline $\mathrm{RDP}$ required & 2,651 & 0 & 2,651 & 2,651 & 2,651 & 0 & 0.0 \\
\hline RDP supplied & 2,791 & 198 & 2,797 & 2,454 & 3,109 & 655 & 23.5 \\
\hline RDP balance & 140 & 198 & 146 & -198 & 457 & 655 & \\
\hline RUP required & 1,670 & 50 & 1,655 & 1,631 & 1,783 & 151 & 9.1 \\
\hline RUP supplied & 1,672 & 169 & 1,661 & 1,414 & 1,971 & 557 & 33.3 \\
\hline RUP balance & 2 & 165 & -4 & -256 & 289 & 545 & \\
\hline MP req. Maint ${ }^{4}$ & 944 & 5 & 942 & 942 & 955 & 13 & 1.4 \\
\hline MP req. Lact ${ }^{5}$ & 2,015 & 0 & 2,015 & 2,015 & 2,015 & 0 & 0.0 \\
\hline MP required & 2,959 & 5 & 2,957 & 2,957 & 2,970 & 13 & 0.5 \\
\hline MP bacterial & 1,427 & 39 & 1,442 & 1,335 & 1,442 & 107 & 7.5 \\
\hline MP RUP & 1,407 & 147 & 1,397 & 1,183 & 1,665 & 482 & 34.2 \\
\hline MP endogenous & 127 & 0 & 127 & 127 & 127 & 0 & 0.0 \\
\hline MP supplied & 2,961 & 139 & 2,955 & 2,744 & 3,203 & 459 & 15.5 \\
\hline MP balance & 2 & 139 & -3 & -214 & 243 & 458 & \\
\hline Total essential AA & 1,579 & 58 & 1,576 & 1,488 & 1,678 & 190 & 12.0 \\
\hline MP allowable milk $(\mathrm{kg})$ & 45 & 3 & 45 & 40 & 50 & 10 & 22.7 \\
\hline
\end{tabular}

$1 \%$ Change $=(95 \%-5 \%) /$ Mean $\times 100$.

${ }^{2}$ Feed_CP $=$ CP of the feedstuff.

${ }^{3}$ Feed_Kd $=$ Kd of protein B fraction in the feedstuff.

${ }^{4} \mathrm{MP}$ requirement for maintenance.

${ }^{5} \mathrm{MP}$ requirement for lactation.

high linear relationships with predicted protein balances, the standardized regression coefficients indicated that their effect on predicted protein balances was relatively small compared with the effect of $\mathrm{Kp}$ concentrate. In this study, $73.5 \%$ of RUP and $51 \%$ of $\mathrm{RDP}$ was from concentrate, which is typical of lactating dairy cow diets in North America. These results indicate that the prediction of $\mathrm{Kp}$ concentrate is the most important $\mathrm{Kp}$ in predicting protein supply with the NRC (2001) model.

Analysis 3: Sensitivity of Protein Outputs for a Lactating Cow by the 2001 Dairy NRC Model to Probability Distributions of Passage Rate, CP, and Kd of Protein B Fraction. Table 9 shows the expected variability in feed $\mathrm{CP}$ values and the $\mathrm{Kd}$ of the protein $B$ fraction based on the means and SD as presented in the feed tables of NRC (2001), and the effect of this variation on model predicted outputs for MCP, RDP, RUP, MP, MP allowable milk, and total essential AA. The Kd of the protein $\mathrm{B}$ fraction have a large variability, with the $90 \%$ confidence interval for all 5 feeds being greater than $97 \%$ of the mean value. The variability in CP (percentage change from mean value) was between $30.3 \%$ (legume hay) and $45.7 \%$ (corn), except for soybean meal where the variability was only $12.8 \%$. These data indicate that variability of the $\mathrm{Kd}$ of the $\mathrm{B}$ fraction of feed $\mathrm{CP}$ is much higher than any other variable evaluated, and thus can cause variation in predictions. Distributions of predicted protein supplies after 9,200 runs to achieve less than $1 \%$ of convergence are also shown in Table 9. Variability of CP, Kd of protein B fraction, and Kp had little or no effect on predicted supplies of MCP and requirements for RDP, RUP, and MP requirements in the model. However, 23.5 and $33.3 \%$ changes in the mean value of the RDP and RUP supplies, respectively, were observed. Consequently, the MP supply and MP allowable milk were changed $459 \mathrm{~g}$ and $10 \mathrm{~kg}$, respectively, with a $90 \%$ confidence interval. Supply of total essential amino acids supply varied $190 \mathrm{~g}$, which was $12 \%$ of the mean. 


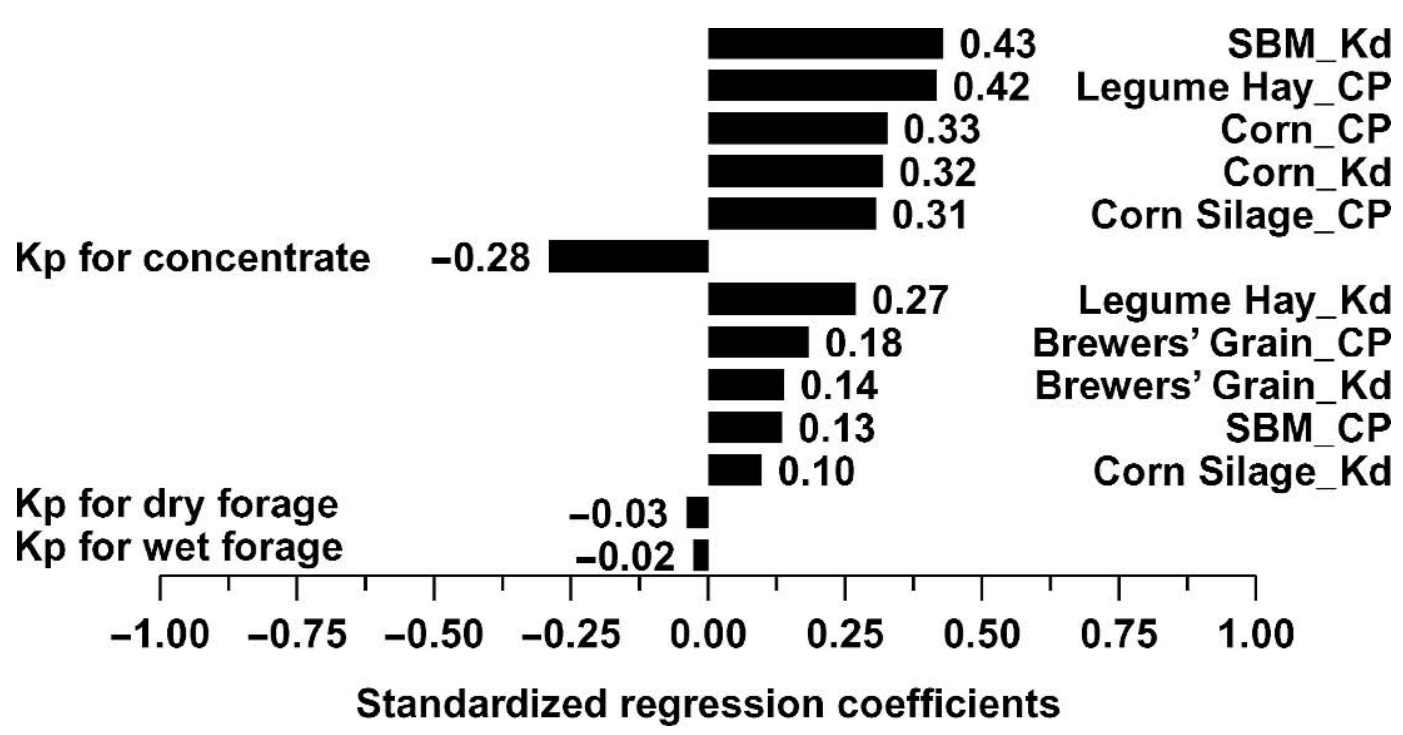

Figure 8. Tornado graph of the sensitivity of RDP supply to variation in feed CP, Kd of protein B fraction, and passage rates in the 2001 Dairy NRC model (analysis 3). Feed_CP means CP of the feedstuff and Feed_Kd means fractional rate of digestion of protein B fraction in the feedstuff.

Tornado graphs in Figures 8 and 9 show the sensitivity of predicted protein outputs to the input variables. The values are standardized regression coefficients, which show the relative importance of the variables. Figure 8 shows that that RDP supplies are negatively correlated with $\mathrm{Kp}$ and positively correlated with the $\mathrm{Kd}$ of the B fraction of feed CP. In contrast, it follows that RUP supplies (and thus MP supplies) are positively correlated with $\mathrm{Kp}$ and negatively correlated with the
Kd of the B fraction of CP (Figure 9). The amount of $\mathrm{CP}$ in feed ingredients was positively correlated with all protein supply variables. The $\mathrm{Kd}$ of the protein $\mathrm{B}$ fraction of SBM had the greatest effect on all measures of protein supply evaluated in this study (Figures 8 and 9). Thereafter, in order of most important to least important in predicting supply of RDP were variations in $\mathrm{CP}$ of legume hay, the CP content of corn, the Kd of the $\mathrm{B}$ fraction of $\mathrm{CP}$ in corn, the CP content of corn

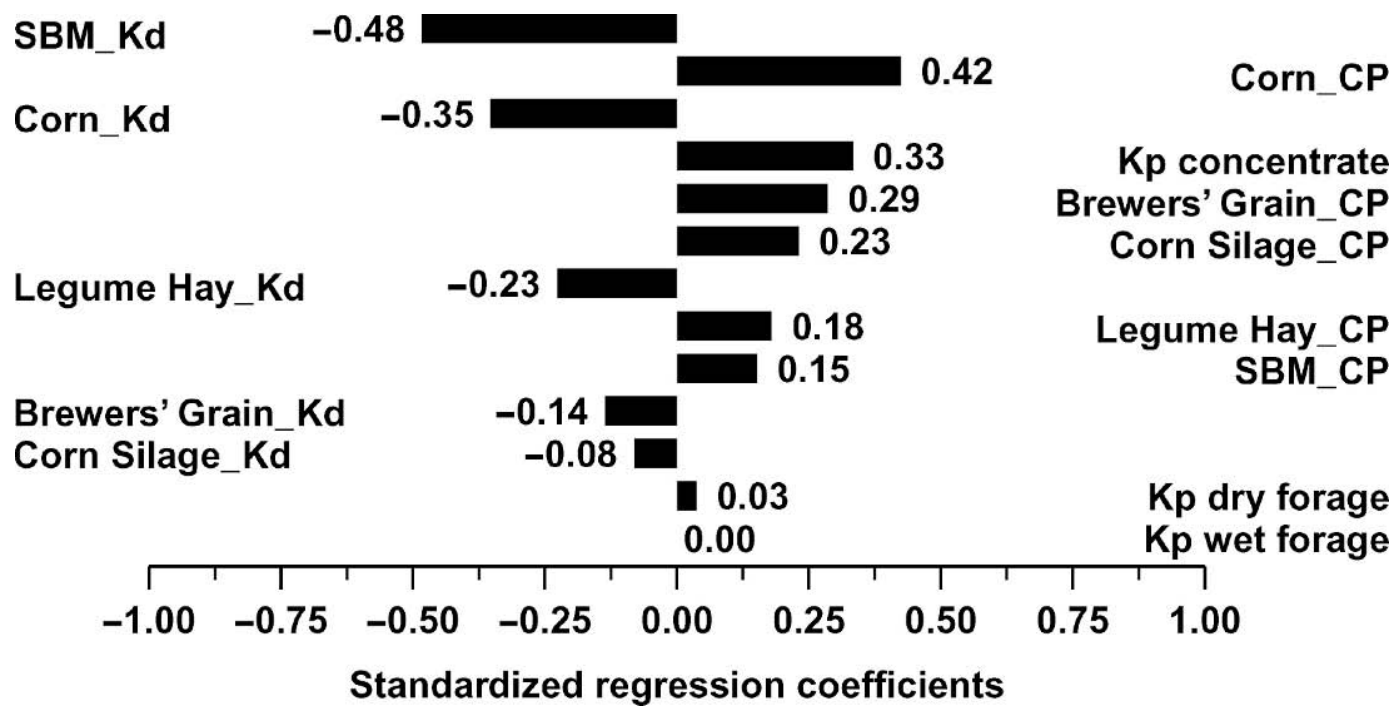

Figure 9. Tornado graph of the sensitivity of RUP supply to variation in feed CP, Kd of protein B fraction, and passage rates in the 2001 Dairy NRC model (analysis 3). Feed_CP means CP of the feedstuff and Feed_Kd means fractional rate of digestion of protein B fraction in the feedstuff. 
silage, the $\mathrm{Kp}$ of concentrates, and the $\mathrm{Kd}$ of the $\mathrm{B}$ fraction of $\mathrm{CP}$ in legume hay (Figure 8). Prediction of RUP was the most sensitive to variations in Kd of SBM (noted above), followed by the $\mathrm{Kd}$ of the $\mathrm{B}$ fraction of $\mathrm{CP}$ in corn, the CP content of corn, the Kp of concentrates and the $\mathrm{Kd}$ of the $\mathrm{B}$ fraction of $\mathrm{CP}$ in legume hay. These data indicate that the relative importance of input variables for each feed ingredient in predicting protein outputs is dependent on its content in feeds (i.e., pool size) in combination with $\mathrm{Kd}$ of protein $\mathrm{B}$ fraction and their variability. Only the Kp for concentrate was highly ranked among the input variables. The $90 \%$ probability of change in $\mathrm{Kp}$ in this simulation was $1.07,1.12$, and $2.54 \% / \mathrm{h}$ for dry forage, wet forage, and concentrate, respectively. The $\mathrm{Kp}$ of concentrate had higher variation than the other two. This may be because it is highly dependent on random variability of DMI as a percentage of BW. When an equation contains a large coefficient for a parameter, the effect of this parameter is greatly amplified when that parameter is highly variable. For example, the parameter estimate for DMI as a percentage of BW was twice as high for the $\mathrm{Kp}$ of concentrate (1.375) than the $\mathrm{Kp}$ for dry forage $(0.479)$ and wet forage (0.614). Higher variability of $\mathrm{Kp}$ of concentrate, as well as the high contribution of protein from concentrate in total dietary protein explains why the $\mathrm{Kp}$ of concentrate was more important than the Kp of dry and wet forages.

The results of this study indicate variation in the NRC (2001) passage rate input variables can result in much variation in predicting protein supply to lactating dairy cattle. As shown in Table 9, a variation in MP allowable milk of $10 \mathrm{~kg}$ is possible due to accumulated variation in the input variables. This sensitivity analysis revealed the importance of accurate determination of $\mathrm{CP}$ and the Kd of the B fraction of CP of each feed ingredient, especially concentrates, and the $\mathrm{Kp}$ of concentrates to accurately predict protein supply and MP allowable milk production.

The results of this study also indicates that the effect of rates of protein digestion and passage of undigested feed on microbial protein production is negligible in the NRC (2001) model if diets are balanced to allow for a small surplus of RDP. For this evaluation of the model, the mean surplus of RDP was $188 \mathrm{~g} / \mathrm{d}$, with surpluses varying between 85 and $300 \mathrm{~g} / \mathrm{d}$ within a $90 \%$ confidence interval (Table 7). Thus, there was limited opportunity for RDP to be limiting and affecting synthesis of microbial protein. Nevertheless, of concern is the fact that research has shown that amino acid nitrogen may enhance microbial production (Russell and Sniffen, 1984; Griswold et al., 1996) and that faster passage rates may increase the efficiency and yield of rumen microbes (Kennedy and Murphy, 1988; Eun et al., 2004). Thus, the simple empirical representation of microbial protein production used in the NRC (2001) model (13\% of TDN) will not accurately account for the dynamics of digestion and passage in the rumen in many situations.

No attempt was made to correct the current passage rate equations for any of the reported values for physical properties, and this may account for some of the lack of fit for regression equations. Physical properties, such as particle size, density, and shear factor may affect the rate of digesta flow out of the rumen. Physical reduction of the particle size of feed ingredients has been shown to alter rumen turnover rate (Evans, 1981b). Rate of passage out of the rumen varies inversely with particle size, or with physical properties like specific gravity that are correlated with particle size within a forage (Murphy and Kennedy, 1993). Sometimes particle density is twice as important as particle length in determining the rate of passage from the rumen (Lechner-Doll et al., 1991). However, the lack of adequate published data and limitations in methodology to quantify physical properties make it difficult to develop equations containing these factors as input variables.

\section{CONCLUSIONS}

The 3 passage rate equations developed by the 2001 Dairy NRC Committee accurately represent the database used to develop them, with correction of the one error in the sign of a coefficient found in the Kp equation for dry forage. The procedures used to develop the parameter estimates provide quantitative relationships between the input variables and fractional rate of passage independent of study variation. Prediction of $\mathrm{Kp}$ is more sensitive to DMI than any other variable, making its determination the most important in predicting rate of passage. Prediction of MP supply to lactating dairy cows is more sensitive to variation in the $\mathrm{Kd}$ of the $\mathrm{B}$ fraction of $\mathrm{CP}$, the content of $\mathrm{CP}$, and the $\mathrm{Kp}$ of concentrates than the same variables in forages. Regression of observations, adjusted for study effect, against predictions for input variables indicated that the equations are appropriate to predict rate of passage. However, it is likely that equations that improve predictions of passage rates could be developed by using appropriate techniques to analyze all passage rate data obtained from the use of both rare earth and chromium mordant as a marker. Development of equations using a random coefficient model may inflate unexplainable error by adding more random variables, while ability of input variables to explain the variation in observations remains the same. To explain more variation in $\mathrm{Kp}$ with predictor variables, other input variables that account 
for physical property of particles need to be incorporated into the model.

\section{REFERENCES}

Agresti, A. 2002. Categorical data analysis. 2nd ed. John Wiley \& Sons, New York, NY.

Campolongo, F., A. Saltelli, T. Sorensen, and S. Tarantola. 2000 Hitchhiker's guide to sensitivity analysis. Pages 16-47 in Sensitivity Analysis. A. Saltelli, K. Chan, and E. M. Scott, ed. Wiley, New York, NY.

Colucci, P. E., G. K. Macleod, W. L. Grovum, I. McMillan, and D. J. Barney. 1990. Digesta kinetics in sheep and cattle fed diets with different forage to concentrate ratios at high and low intakes. J. Dairy Sci. 73:2143-2156.

Eun, J. S., V. Fellner, and M. L. Gumpertz. 2004. Methane production by mixed ruminal cultures incubated in dual-flow fermentors. J. Dairy Sci. 87:112-121.

Evans, E. 1981a. An evaluation of the relationships between dietary parameters and rumen liquid turnover rate. Can. J. Anim. Sci. 61:91-96.

Evans, E. 1981b. An evaluation of the relationships between dietary parameters and rumen solid turnover rate. Can. J. Anim. Sci. 61:97-103.

Frey, H. C., and S. R. Patil. 2002. Identification and review of sensitivity analysis methods. Risk Anal. 22:553-578.

Griswold, K. E., W. H. Hoover, T. K. Miller, and W. V. Thayne. 1996. Effect of form of nitrogen on growth of ruminal microbes in continuous culture. J. Anim. Sci. 74:483-491.

Grovum, W. L. 1986. The control and motility of the ruminoreticulum. Pages 18-40 in Control of digestion and metabolism in ruminants: Proc. Sixth Int. Symp. Rumin. Physiol. L. P. Milligan, W. L. Grovum, and A. Dobson, ed. Prentice-Hall, Englewood Cliffs, NJ.

Helton, J. C., and F. J. Davis. 2000. Sampling-based methods. Pages 101-153 in Sensitivity analysis. A. Saltelli, K. Chan, and E. M. Scott, ed. Wiley, New York, NY.

Kennedy, P. M., and P. T. Doyle. 1993. Particle-size reduction by ruminants-effects of cell wall composition and structure. Pages 499-533 in Forage cell wall structure and digestibility. H. G. Jung, United States. Agricultural Research Service, and U.S. Dairy Forage Research Center, ed. American Society of Agronomy Inc.: Crop Science Society of America Inc.: Soil Science Society of America Inc., Madison, WI.

Kennedy, P. M., and M. R. Murphy. 1988. The nutritional implications of differential passage of particles through the ruminant alimentary tract. Nutr. Res. Rev. 1:189-208.
Lechner-Doll, M., M. Kaske, and W. V. Engelhardt. 1991. Factors affecting the mean retention time of particles in the forestomach of ruminants and camelids. Pages 455-482 in Physiological aspects of digestion and metabolism in ruminants: Proc. Seventh Int. Symp. Rumin. Physiol. T. Tsuda, Y. Sasaki, and R. Kawashima, ed. Academic Press, San Diego, CA.

Littell, R. C., W. W. Milliken, W. W. Stroup, and R. D. Wolfinger. 1999. SAS System for Mixed Models. SAS Institute Inc., Cary, NC.

Mowrey, A., and J. N. Spain. 1999. Results of a nationwide survey to determine feedstuffs fed to lactating dairy cows. J. Dairy Sci. 82:445-451.

Murphy, M. R., and P. M. Kennedy. 1993. Particle dynamics. Pages 87-105 in Quantitative aspects of ruminant digestion and metabolism. J. M. Forbes and J. France, ed. CAB International, Wallingford, Oxon, UK.

Neter, J., M. H. Kutner, C. J. Nachtsheim, and W. Wasserman. 1996. Applied linear statistical models. 4th ed. McGraw-Hill Publishing, Boston, MA.

NRC. 2001. Nutrient Requirements of Dairy Cattle. 7th rev. ed. Natl. Acad. Press, Washington, DC.

Offer, N. W., and J. Dixon. 2000. Factors affecting outflow rate from the reticulo-rumen. Nutr. Abstr. Rev. 70:833-844.

Owens, F. N., and A. L. Goetsch. 1986. Digesta passage and microbial protein synthesis. Pages 196-223 in Control of digestion and metabolism in ruminants: Proc. Sixth Int. Symp. Rumin. Physiol., Banff, Canada. A. Dobson, ed. Prentice-Hall, Englewood Cliffs, NJ.

Russell, J. B., and C. J. Sniffen. 1984. Effect of carbon-4 and carbon5 volatile fatty acids on growth of mixed rumen bacteria in vitro. J. Dairy Sci. 67:987-994.

SAS Institute. 2002. User's guide: Statistics, Version 9 ed. SAS Institute, Inc., Cary, NC.

St-Pierre, N. R. 2001. Invited review: Integrating quantitative findings from multiple studies using mixed model methodology. J. Dairy Sci. 84:741-755.

Sutton, A. J. 2000. Methods for meta-analysis in medical research. John Wiley, Chichester, West Sussex, UK.

Tylutki, T. P. 2002. Improving herd nutrient management on dairy farms: 1) Individual cow milk production variance, 2) Developing a quality management program on a commercial dairy farm, a six sigma approach, 3) Variation in nutrient content of feeds on a commercial dairy farm, 4) Predicting phosphorus excretion by dairy cattle, 5) Incorporating risk in managing dairy cattle nutrition. Ph.D. Dissertation, Cornell University, Ithaca, NY.

Van Soest, P. J. 1994. Nutritional ecology of the ruminant. 2nd ed. Comstock Pub., Ithaca, NY.

Welch, J. G. 1982. Rumination, particle size and passage from the rumen. J. Anim. Sci. 54:885-894. 